\title{
Transient Numerical Analysis of Free Convection in Cylindrical Enclosure
}

\author{
Mohamed Amine Medebber ${ }^{1,2, *}$, Nourddine Retiel ${ }^{2}$, belkacem Ould said ${ }^{2}$, Abderrahmane Aissa ${ }^{l}$, and Mohammed El \\ Ganaoui $^{3}$ \\ ${ }^{1}$ Mechanical Engineering Departments, Mostapha Istambouli University, Mascara, Algeria. \\ ${ }^{2}$ Laboratory Numerical and Experimental Modeling of Mechanical phenomena, Mechanical Engineering Department, Abdelhamid Ibn \\ Badis University, Mostaganem, Algeria. \\ ${ }^{3}$ Laboratoire énergétique de Longwy (FJV/LERMAB), Université de Lorraine, France
}

\begin{abstract}
A transient two dimensional study of free convection in a vertical cylinder partially annulus is conducted numerically. Uniform temperature is imposed cross a vertical wall, while the top and bottom walls are adiabatic. The governing equations are solved numerically by using a finite volume method. The coupling between the continuity and momentum equations is effected using the SIMPLER algorithm. Solutions have been obtained for Prandtl numbers equal to 7.0, Rayleigh numbers of $10^{3}$ to $10^{6}$ and height ratios 0.5 . The influence of physical and geometrical parameters on the isotherms, velocity fields, average Nusselt has been numerically investigated.
\end{abstract}

\section{Introduction}

The problem of natural convection of fluids confined in annulus cylinder has been the subject of many studies. This is due to the important role it plays in many technical and engineering applications such as, solar energy collectors, nuclear engineering, cooling of electrical and electronic components, and so on. Many researchers focused their investigation on the heat transfer and fluid flow behavior in a vertical annulus cylinder. One of the first, well documented studies the natural convection in vertical annular enclosures was presented by Vahl Davis et al. [1] numerically studied the natural convection in annulus, and their results were further extended by other authors, including Prasad et al. [2], Kumar et al. [3], and Prasad. [4]. It was found that the annulus curvature can strongly affect the flow structure and the heat transfer. Y.L. He et al. [5] studied the natural convection heat transfer and fluid flow in a vertical cylindrical envelope with adiabatic lateral wall. They founded that, for the small cases $\Delta \mathrm{T}_{\mathrm{W}}=25 \mathrm{~K}$, studied ( $\mathrm{Ra}=1.1 \times 10^{5} \sim 4 \times 10^{7}$ ), there is a global circulation between the hot and cold ends, accompanied by some local recirculations in the envelope. For the large temperature difference case $\Delta \mathrm{T}_{\mathrm{W}}=220 \mathrm{~K}$, with the decrease in $\mathrm{L} / \mathrm{D}$, the average heat transfer rate increases.

In experimental studies, A. H. Malik et al. [6] investigated experimentally and numerically the buoyancy driven flow within bottom heated vertical concentric cylindrical enclosure. The experimental and numerical study of the axial temperature gradient and the heat transfer mechanism within the enclosure were performed. They showed that the numerical results of the streamlines within the enclosure depicted the real picture of the buoyancy effects. Nilesh B.Totala et al. [7] studied experimentally natural convection through vertical cylinder. The local heat transfer coefficient along the length of cylinder is determined experimentally and is compared with theoretical value obtained by using appropriate governing equations. They concluded that the heat transfer coefficient is having maximum value at the beginning length of cylinder and decrease in upward direction. R. Hosseini et al. [8] experimentally studied the natural convection heat transfer from a long heated vertical cylinder to an adjacent air gap of concentric and eccentric conditions. The aspect and diameter ratios of the cylinder are 55.56 and 6.33 , respectively. The experimental measurements were obtained for a concentric condition and six eccentricities from 0.1 to 0.92 at five different heat fluxes. The surface temperature of the heated rod is measured at different heights, and the Nusselt number is calculated at the temperature measurement locations. A correlation is suggested to determine the Nusselt number based on the variation of the eccentric ratio values. They showed that the heat transfer rate is greater for eccentric pipes. At low heat flux, the temperature along the rod is almost constant, and when heat flux increases, temperature increases.

\footnotetext{
* Corresponding author: amine mg@yahoo.fr
} 
To investigate the stability of natural convection in an annular cavity, K.Choukairy et al. [9] studied numerically the effect of an obstacle on the heat transfer. The obstacle modifies the flow structure and affects local transfers. This change is more pronounced in a cylindrical configuration given the asymmetry resulting flows. The configuration considered is that of a cavity annular where the vertical walls are differentially heated and the horizontal walls are adiabatic. The effect of the size and conductivity of the obstacle on the transfer are analyzed when it has a low conductivity (insulating) or high conductivity. The obstacle is placed near the inner cylinder and its thickness variable. Numerical results show that the inclusion of obstacle modifies the overall flow and therefore local transfers. P. Venkata Reddy et al. [10] numerically investigated the natural convection in a vertical annulus driven by a central heat generating rod. The primitive equation is solved using a pressurecorrection algorithm. They varied the heat generation based Grashof number, aspect ratio and the solid-to-fluid thermal conductivity ratio over wide ranges with the Prandtl number fixed at 0.7. They founded that the average Nusselt numbers on the inner and outer boundaries increase with the Grashof number. M. Sankar.et al. [11] numerically investigated the natural convection in a vertical annulus with a localized heat source. A discrete heater is placed at the inner wall, while the top and bottom walls as well as the unheated portions of the inner wall are kept adiabatic, and the outer wall is maintained at a lower temperature. They founded that the placement of heater near the middle portion of inner wall yields a maximum heat transfer and minimum near the top and bottom portions of the inner wall. Further, they founded that the rate of heat transfer is an increasing function of radii ratio of the annulus.

A part of research has shifted their attention to understanding the mechanism of heat and mass transfer in annular enclosures, Sheng Chen et Jonas Tölke. [12] numerically investigated the double-diffusive convection in vertical annuluses with opposing temperature and concentration gradients for higher Rayleigh numbers up to $10^{7}$ using a simple lattice Boltzmann model for buoyancy ratio forces $0.8 \leq \mathrm{N} \leq 1.3$, the aspect ratio $0.5 \leq \mathrm{A} \leq 2$ and the radius ratio $1.5 \leq \mathrm{K} \leq 3$. The results showed that the convective flows with $\mathrm{Ra}=10^{6}$ and $\mathrm{N}<1.0$, there is only one large clockwise thermal recirculation in the enclosure, independent of $\mathrm{K}$ and $\mathrm{A}$. On the contrary, the number of vortices varies depending on $\mathrm{K}$ and $\mathrm{A}$ when $\mathrm{N}>1.0$. The average Nusselt number $\mathrm{Nu}$ and the average Sherwood number Sh are monotonic increasing functions of $\mathrm{K}$. Jiten $\mathrm{C}$ Kalita et al. [13] numerically studied the Double-diffusive natural convection in a vertical porous annulus using the Higher
Order Compact (HOC) algorithm. The flow is investigated in the regime $-50 \leq \mathrm{N} \leq 50,1 \leq \mathrm{A} \leq 10,1 \leq \mathrm{k} \leq 50$, $0 \leq \mathrm{Ra} \leq 10^{3}$ and $1 \leq \mathrm{Le} \leq 500$, where $\mathrm{N}, \mathrm{A}, \mathrm{k}, \mathrm{Ra}$ and Le are the buoyancy ratio, aspect ratio, radius ratio, thermal Rayleigh number and Lewis number respectively. The results revealed that the strength of the general convective movement increases with increasing $\mathrm{Ra}$ and the development of boundary layers is also seen with increase in $\mathrm{N}$, for larger values of $\mathrm{N}$, a large portion of the core of the annulus is seen to be stagnant because of the blocking effect of the combined effect of vertical. M. Sankar et al. [14] analyzed the double-diffusive convection in a fluid saturated vertical porous annulus subjected to discrete heat and mass fluxes from a portion of the inner wall. The physical model for the momentum equation is formulated using the Darcy law, and the resulting governing equations are solved using an implicit finite difference technique. Rajesh Sharma et al. [15] have studied the coupled momentum and heat transfer in unsteady, incompressible flow along a semi-infinite vertical porous moving plate adjacent to an isotropic porous medium with viscous dissipation effect. The finite element method (FEM) is utilized to simulate the unsteady free convection flow of a viscous fluid. Recently, M. Sankar et al. [16] have been numerically investigated the natural convection from the linearly heated inner and/or outer walls of a vertical annular cavity. They considered two different thermal boundary conditions, to understand the effect of non-uniform heating of inner and/or outer walls on the convective flow, the local and global heat transfer rate. They founded that the local and average Nusselt numbers strongly depends on the thermal boundary conditions. The rate of heat transfer increases steadily with Rayleigh number and radius ratio.

In contrast with steady natural convection, transient analysis of natural convection in a vertical cylindrical cavity has received much attention in the literature, $\mathrm{K}$. Choukairy et al. [17] studied numerically and analytically the transient laminar free convection in a vertical cylindrical annulus filled with air $\operatorname{Pr}=0.71$. The result showed that the required time to reach steady state decreases with the convection intensity and is independent of the curvature. Anil Kumar Sharma et al. [18] studied numerically the transient turbulent natural convection heat transfer from a volumetric energy generating source placed inside a cylindrical enclosure filled with low Prandtl number fluid $\mathrm{Pr}=0.005$. Amitesh Kumar et al. [19] numerically investigated unsteady axisymmetric laminar natural convection in a vertical cylindrical enclosure laterally heated at the vertical wall for different aspect ratios 2-4, and different Prandtl numbers of $0.01 \leq \operatorname{Pr} \leq 10$. They showed that for low 
Prandtl number fluids, $\operatorname{Pr}<1.0$, critical Rayleigh number increase with increase in aspect ratio while for high Prandtl number fluids, $\operatorname{Pr}>1.0$, decrease with increase in aspect ratio. D.E. Ameziani et al. [20] have been studied the problem of unsteady natural convection heat transfer in a vertical opened porous cylinder submitted to a sinusoidal time variation temperature on the lateral wall. The study is carried out using the Darcy flow model and the set of equations is resolved by the finite volumes method. They showed that the comparison between the simulations obtained with the constant wall temperature and the sinusoidal time variation, demonstrates non significant difference (less than 3\%) for low dimensionless amplitudes $(\mathrm{XA}<0.5)$. When the amplitude rises above $\mathrm{XA}>0.5$, the relative heat transfer enhancement increases with XA and Ra.

Based on the above-mentioned works, and published results according to our best knowledge that there is no works has been published yet, devoted to studying features of free convection heat transfer in such geometry $(\mathrm{X}=\mathrm{h} / \mathrm{H}=0.5)$ : the inner cylinder height is different than the outer cylinder one. Therefore, we focus our attention to study the transient steady laminar free convection heat transfer in a cylindrical cavity partially annular filled with water $\operatorname{Pr}=7.0$. The aim here was to calculate the time dependent flow in an annular space and discussed the numerical computations results

\section{Mathematical Formulation}

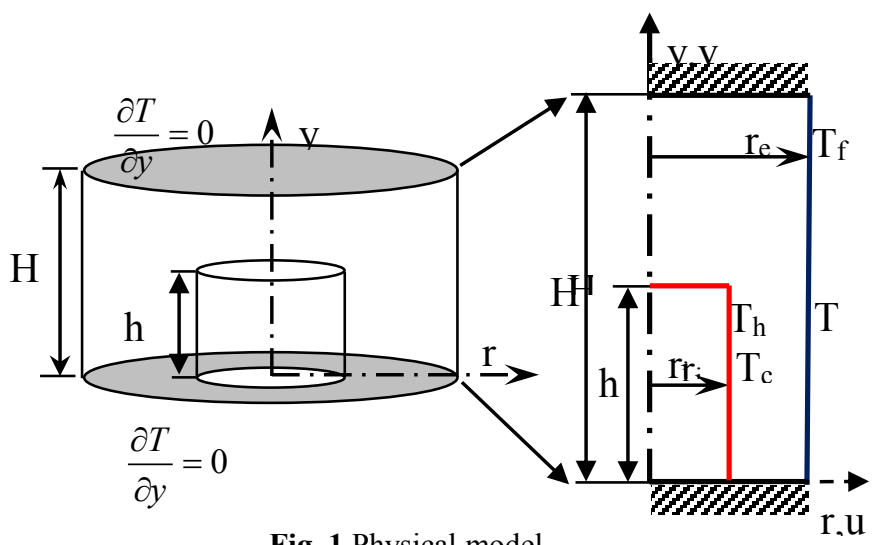

Fig. 1 Physical model

The configuration under investigation is represented in Figure 1 and consists of a vertical annulus of height outer cylinder $\mathrm{H}$, outer radius $\mathrm{r}_{0}$, and height inner cylinder $\mathrm{h}$, inner radius $r_{i}$. The vertical walls are maintained at different uniform hot and cold temperatures, $T_{h}$ and $T_{c}$, respectively. The top and bottom walls of the enclosure are thermally insulated expect the horizontal wall of inner cylinder is maintained at hot temperature. It is assumed that the flow is incompressible and laminar, and the fluid is Newtonian, no viscous heat dissipation. The thermophysical properties of the fluid are assumed to be constants, except density in the buoyancy term, which depends linearly on the local temperature, i.e., the
Boussinesq approximation is assumed to be valid. The annular gap width $\Delta r=r_{0}-r_{i}$ is taken as a reference length for the spatial coordinates $(R, Y)=\frac{(r, y)}{\left(r_{0}-r_{i}\right)}$. The references for velocity, pressure, time and temperature are defined as $(U, V)=\frac{(u, v)\left(r_{0}-r_{i}\right)}{v}, P=\frac{p\left(r_{0}-r_{i}\right)^{2}}{\rho v^{2}}$, $\tau=\frac{t v}{\left(r_{0}-r_{i}\right)^{2}}$ and $\theta=\frac{\left(T-T_{0}\right)}{\Delta T}$, with $T_{0}=\frac{T_{h}-T_{c}}{2} \cdot \mathrm{u}, \mathrm{v}$, $v, \rho, g$ presente the $\mathrm{r}$ and $\mathrm{y}$ velocity coordinate, fluid viscosity, fluid density, and gravitational acceleration, respectively.

The governing dimensionless equations for continuity, momentum, and energy can be written as:

$\frac{1}{R} \frac{\partial(R U)}{\partial R}+\frac{\partial V}{\partial Y}=0$

$\frac{\partial U}{\partial \tau}+U \frac{\partial U}{\partial R}+V \frac{\partial U}{\partial Y}=-\frac{\partial P}{\partial R}+\nabla^{2} U-\frac{U}{R^{2}}$

$\frac{\partial V}{\partial \tau}+U \frac{\partial V}{\partial R}+V \frac{\partial V}{\partial Y}=-\frac{\partial P}{\partial Y}+\nabla^{2} V+\frac{R_{a T}}{\operatorname{Pr}} \theta$

$\frac{\partial \theta}{\partial \tau}+U \frac{\partial \theta}{\partial R}+V \frac{\partial \theta}{\partial Y}=\frac{1}{\operatorname{Pr}} \nabla^{2} \theta$

Where

$\nabla^{2}=\frac{\partial}{R \partial R}\left(R \frac{\partial}{\partial R}\right)+\frac{\partial^{2}}{\partial Y^{2}}$

The nondimensionalization process results in the following control parameters:

$$
\begin{aligned}
& A=\frac{H}{\left(r_{0}-r_{i}\right)}=\frac{H}{\Delta r}, \quad a=\frac{h}{\left(r_{0}-r_{i}\right)} \quad, \quad X=\frac{h}{H}=\frac{a}{A} \quad \text { and } \\
& K=\frac{r_{0}}{r_{i}} \\
& R a=\frac{g \beta \Delta T \Delta r^{3}}{v \alpha} \quad \operatorname{Pr}=\frac{v}{\alpha}
\end{aligned}
$$

$\mathrm{A}$ is the aspect ratio of the cavity, $\mathrm{K}$ is the radii ratio of the curvature, $\mathrm{Ra}$ is the thermal Rayleigh number, and $\mathrm{Pr}$ is the Prandtl number.

Equations (1)-(4) are subject to the following initial and boundary conditions:

$$
\begin{aligned}
& \tau=0, \quad U=V=P=\theta=0 \\
& R=\frac{1}{K-1} \text { and } 0<\mathrm{Y}<\mathrm{a}, \theta=0.5 \text { and } \mathrm{U}=\mathrm{V}=0 \\
& R=\frac{K}{K-1} \text { and } 0<\mathrm{Y}<\mathrm{A} \quad, \theta=-0.5 \\
& \mathrm{U}=\mathrm{V}=0
\end{aligned}
$$




$$
\begin{aligned}
& \mathrm{Y}=0 \text { and } \frac{1}{K-1} \leq R \leq \frac{K}{K-1} \quad, \frac{\partial \theta}{\partial Y}=0 \\
& \mathrm{U}=\mathrm{V}=0 \\
& \mathrm{Y}=\mathrm{A} \text { and } 0 \leq R \leq \frac{K}{K-1} \quad, \frac{\partial \theta}{\partial Y}=0 \text { and } \\
& \mathrm{U}=\mathrm{V}=0 \\
& \mathrm{Y}=\mathrm{a} \text { and } 0 \leq R \leq \frac{1}{K-1}, \theta=0.5 \quad \text { and } \quad \mathrm{U}=\mathrm{V}=0
\end{aligned}
$$

As our study area is symmetrical about the vertical axis (OY) (Fig.1), the calculation is based on half of the area containing the fluid. The boundary conditions at the axis of symmetry (OY) become:

$$
\mathrm{R}=0 \text { and } a<\mathrm{Y}<\mathrm{A} \quad \frac{\partial \theta}{\partial R}=0, \frac{\partial V}{\partial R}=0 \text { and } \mathrm{U}=0
$$

The average rate of heat transfer across the inner $\left(r_{i}\right)$ and external $\left(r_{0}\right)$ cylinders are expressed by using the respective Nusselt numbers.

$$
\begin{aligned}
& \mathrm{Nu}_{\mathrm{i} 1}=\left.\frac{\partial \theta}{\partial R}\right|_{R=\frac{1}{K-1}} \partial Y \quad \text { and } \mathrm{Nu}_{\mathrm{i} 2}=\left.\frac{\partial \theta}{\partial Y}\right|_{Y=a} \partial R \\
& \overline{\mathrm{Nu}_{\mathrm{i}}}=\left.\frac{1}{a} \int_{0}^{a} \frac{\partial \theta}{\partial R}\right|_{R=\frac{1}{K-1}} \partial Y+\left.\frac{1}{R} \int_{0}^{R=\frac{1}{K-1}} \frac{\partial \theta}{\partial Y}\right|_{Y=a} \partial R
\end{aligned}
$$$$
\overline{\mathrm{Nu}_{0}}=\left.\frac{1}{A} \int_{0}^{A} \frac{\partial \theta}{\partial R}\right|_{R=\frac{K}{K-1}} \partial Y
$$

\subsection{Numerical procedure}

A finite-difference numerical solution technique based on integration over a control volume is used to solve Eqs. (1)-(4) S. Patankar [21]. The SIMPLER algorithm is used for the pressure- velocity coupling in the momentum equation. The convergence of the algorithm is reached when the residual of the momentum equations and the average quadratic residues of each governing equation evaluated on the whole computational domain is less than $10^{-7}$.

\subsection{Sensitivity grid study.}

The physical domain is discretized into a non-uniform grid, which ensures grid spacing close to the walls, and a coarser mesh system in the core region (Fig.2.a). In order to study the effect of the grid size on the final solution, sensitivity study was conducted by comparing the vertical velocity profiles for different mesh (Fig.2.b).

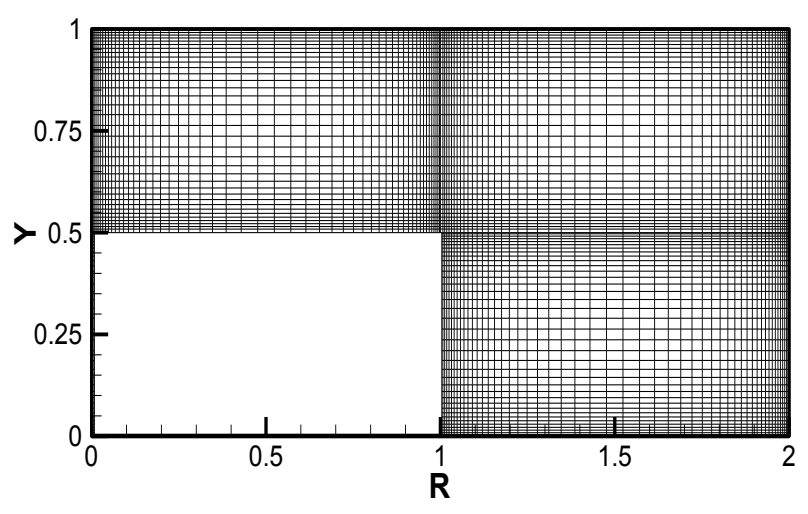

Fig.2.a: Irregular mesh to an annular cavity (109x77) $\mathrm{A}=1, \mathrm{X}=0.5$ and $\mathrm{K}=2$

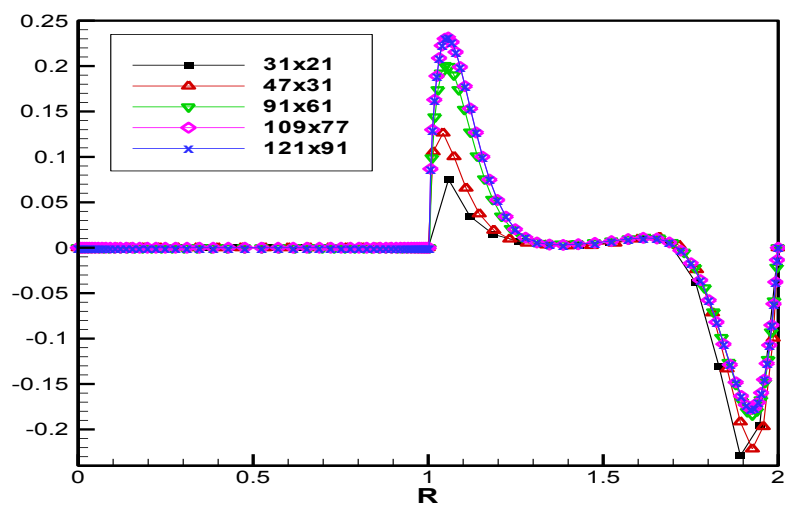

Fig.2.b. Vertical velocity profile at $Y=0.5$ for different grids $\left(\mathrm{Ra}=10^{5}, \mathrm{Pr}=0.71, \mathrm{~A}=1, \mathrm{~K}=2, \mathrm{X}=0.5\right)$

\subsection{Validation}

The computer code was validated with published numerical results on natural convection. The steady-state results have been compared with the benchmark results given by R.Kumar et al [3] and G. Vahl Davis et al [1] in the natural convection case corresponding to $\mathrm{X}=\mathrm{h} / \mathrm{H}=1$.

Table 1: Comparison of the average Nusselt number $A=10$, $\mathrm{K}=2, \mathrm{X}=1.0$ and $\mathrm{Pr}=0.7$.

\begin{tabular}{cccc}
\hline $\begin{array}{c}\text { Nombre de } \\
\text { Rayleigh }\end{array}$ & $\begin{array}{c}\text { Présent } \\
\text { travail }\end{array}$ & $\begin{array}{c}\text { R.Kumar } \\
\text { et al }\end{array}$ & $\begin{array}{c}\text { De Vahl Davis } \\
\text { et al }\end{array}$ \\
\hline $10^{4}$ & 2.361 & 2.355 & 2.333 \\
\hline $5.10^{4}$ & 3.702 & 3.718 & 3.758 \\
\hline $10^{5}$ & 4.535 & 4.558 & 4.568 \\
\hline
\end{tabular}

The comparison is good and the relative error on the average Nusselt number compared to the values proposed by the different authors is around $1 \%$ (Table 1 ).

\section{Result and discussion}

In this section, the time dependence on the convective flow and heat transfer characteristics has been investigated in a vertical annulus space. The results are 
displayed through, isotherms, velocity, temperature and average Nusselt number profiles.

In this study, the parameters such as height ratio, diameter ratio, Rayleigh number and Prandtl number are respectively fixed as $\mathrm{X}=0.5, \mathrm{~K}=2, \mathrm{Ra}=10^{5}$ and $\mathrm{Pr}=7.0$.

The present investigation will be directed toward the time histories of the interior flow and temperature fields as well as the rate of heat transfer on the cavity walls. Figure 3 illustrates the evolution of isotherm for $\mathrm{Ra}=10^{5}, \mathrm{X}=0.5$, $\operatorname{Pr}=7.0$ and $K=2$. In this case the flow near the hot, lefthand wall is driven vertically upward, and downward the cold temperature at the right-hand wall. Clearly, the thermal buoyancy forces push the fluid clockwise and thus they simultaneously accelerate the flow. The effects of the Rayleigh number on the temporal developments of the flow, temperature and velocity fields are of particular interest and discussed below.

$\tau=1$

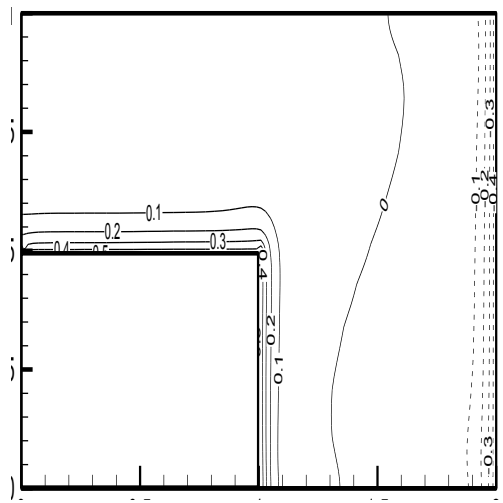

$\tau=4$

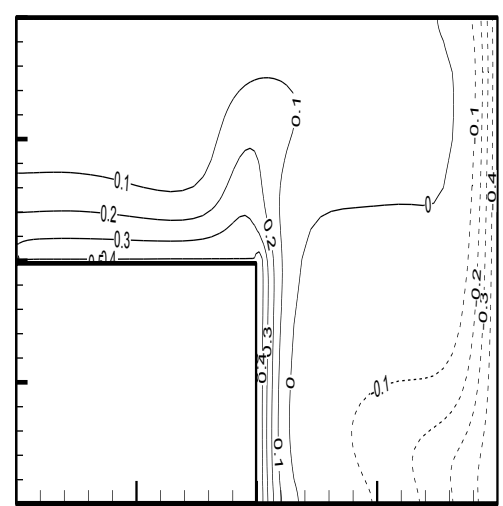

$\tau=2$

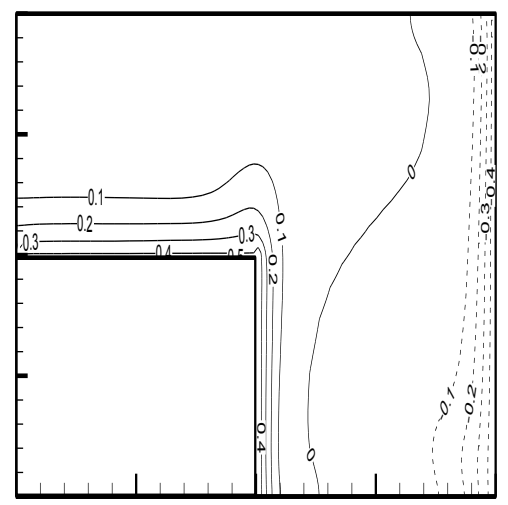

$\tau=5$

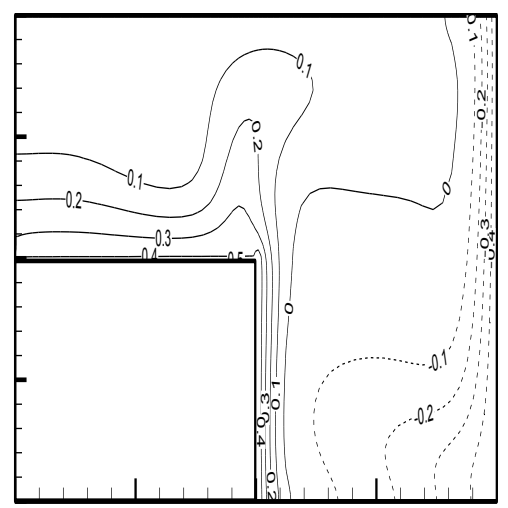

$\tau=3$

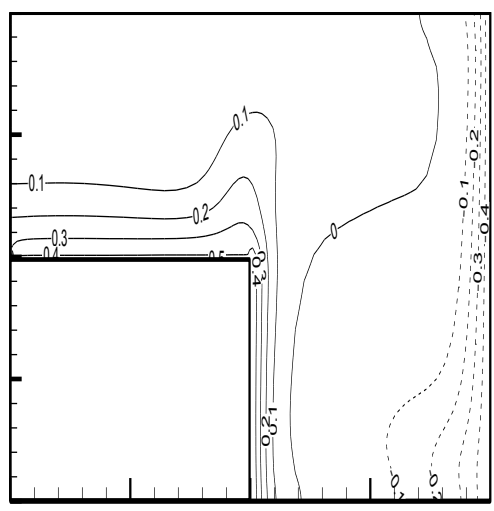

$\tau=6$

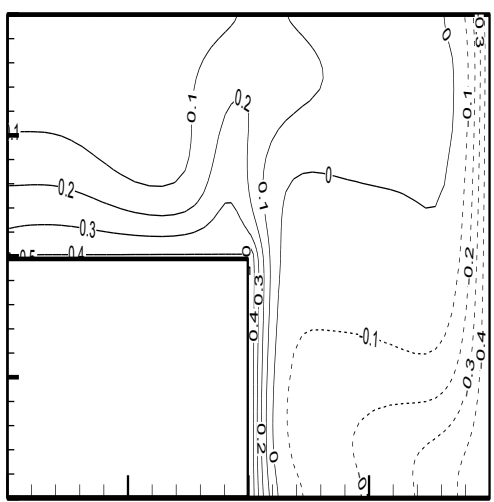



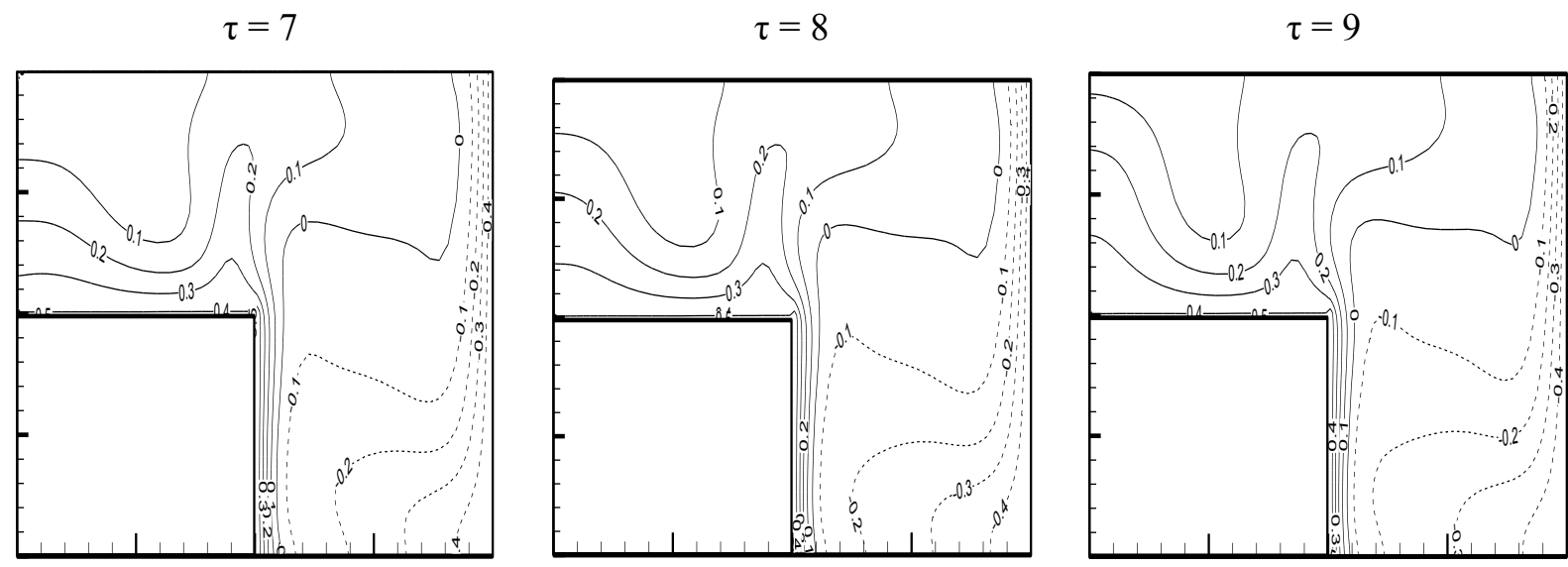

$\tau=10$

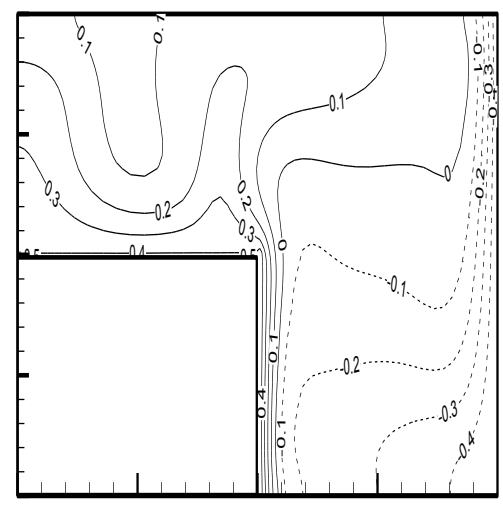

$\tau=19$

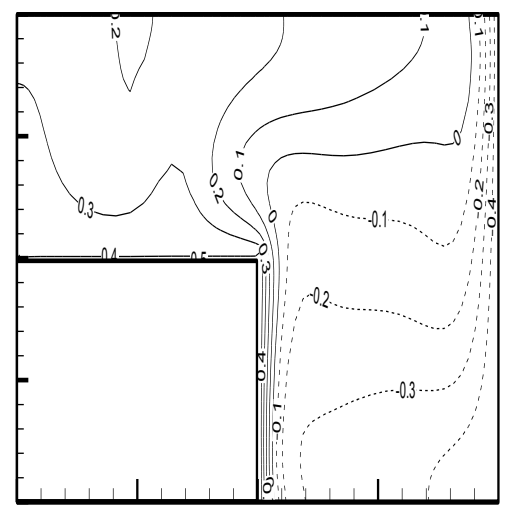

$\tau=13$

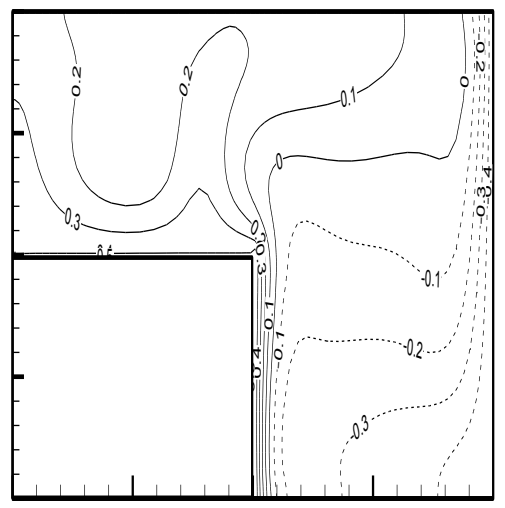

$\tau=20$

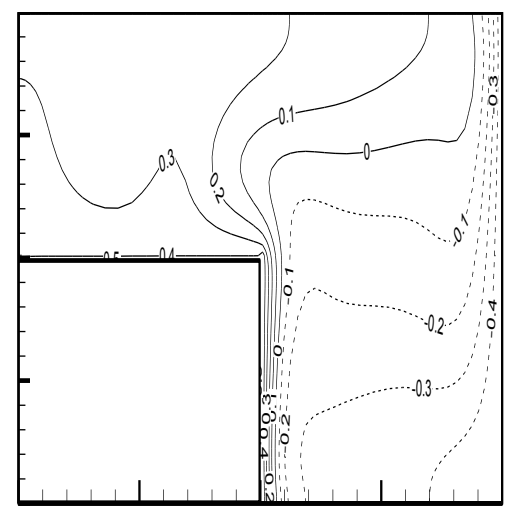

$\tau=14$

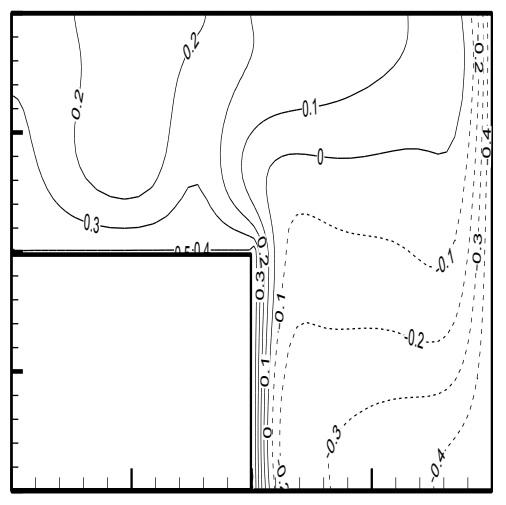

$\tau=29$

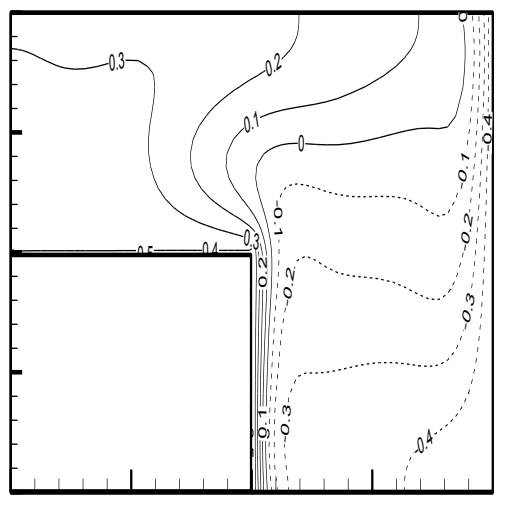



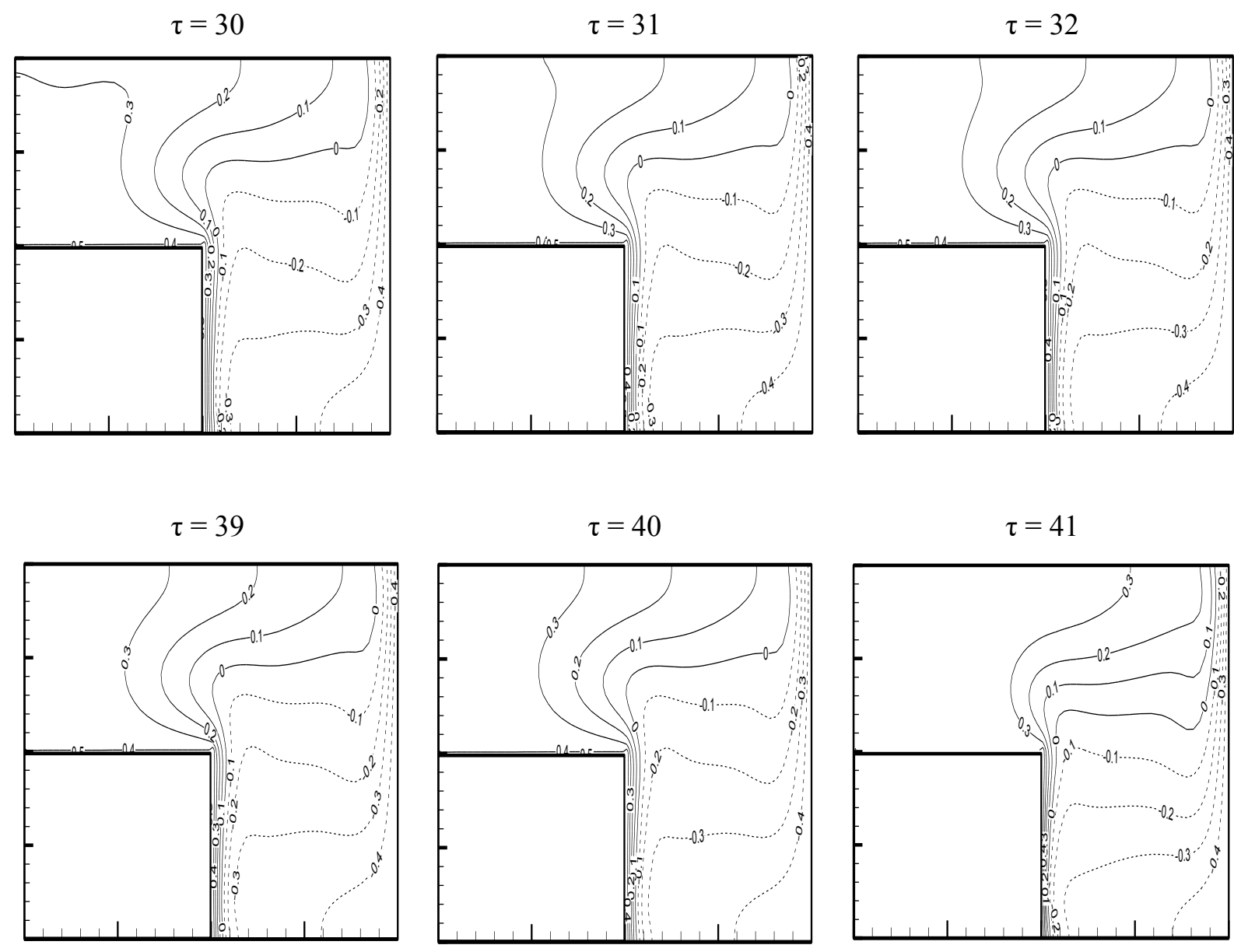

\section{$\tau=42$}

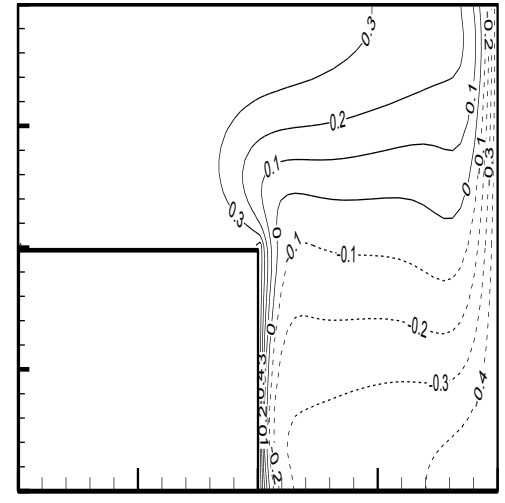

$\tau=43$

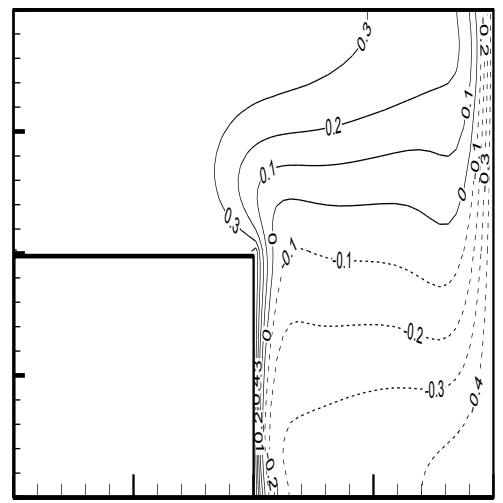

$\tau=44$

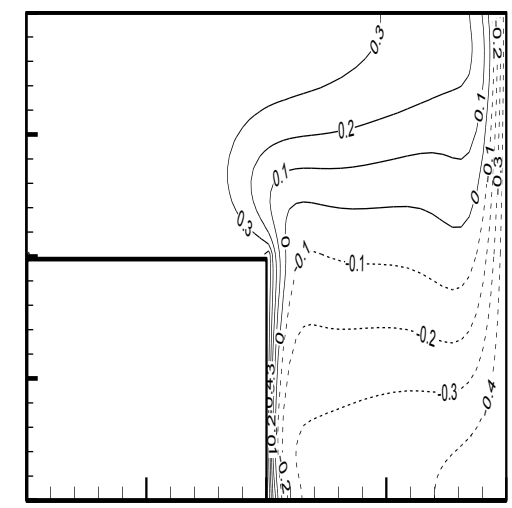

Fig 3: The evolution of isotherm at various dimensionless step times $(\tau)$ for $\mathrm{Ra}=10^{5}, \mathrm{~K}=2, \mathrm{X}=0.5, \mathrm{Pr}=7.0$ 
Next, the time evolution of temperature and velocity at several selected points have been showed in Fig. $(4,5,6)$ for $\mathrm{Ra}=10^{5}, \mathrm{X}=0.5, \mathrm{Pr}=7.0$. Figures 4 illustrate the transient developments of dimensionless temperature $(\theta)$ at differences observation pointes, point (A) located at $\mathrm{R}=0.0$ and $\mathrm{Y}=0.8$ (upper region of hot inner cylinder), point (B) located at $\mathrm{R}=1.65$ and $\mathrm{Y}=0.8$ (core region toward top horizontal surface), point (C) located at $R=1.65$ and $Y=0.8$ (core region close top horizontal surface). Where step times $(\tau)$ varies from 1 to 70 . It is

observed in fig. $(4,5)$ that there is a big change in $U$ and $\theta$ before $\tau=10$ for all computations. Thus, the results for $\tau=10$ are essentially the steady-state values.

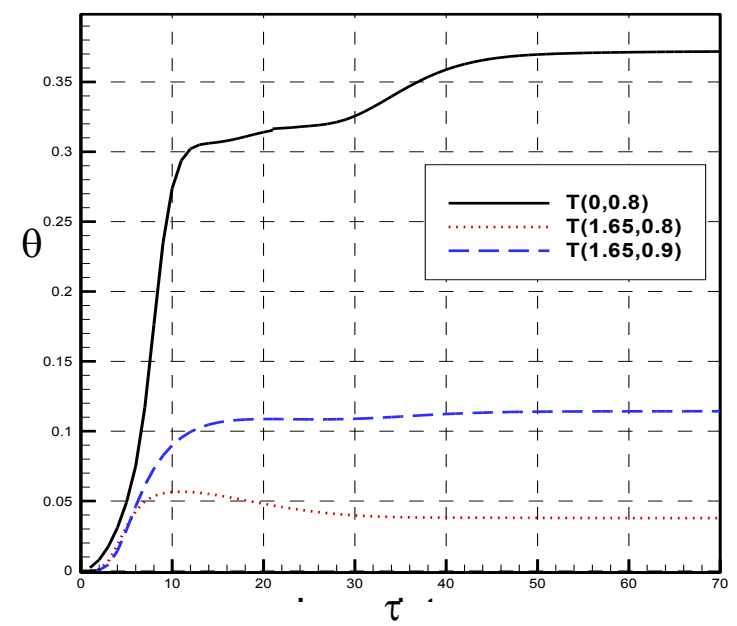

Fig 4: Plots of temperature versus dimensionaless time at three points $\mathrm{A}(0,0.8), \mathrm{B}(1.65,0.8), \mathrm{C}(1.65,0.9)$ for $\mathrm{Ra}=10^{5}, \mathrm{X}=0.5, \mathrm{~K}=2$

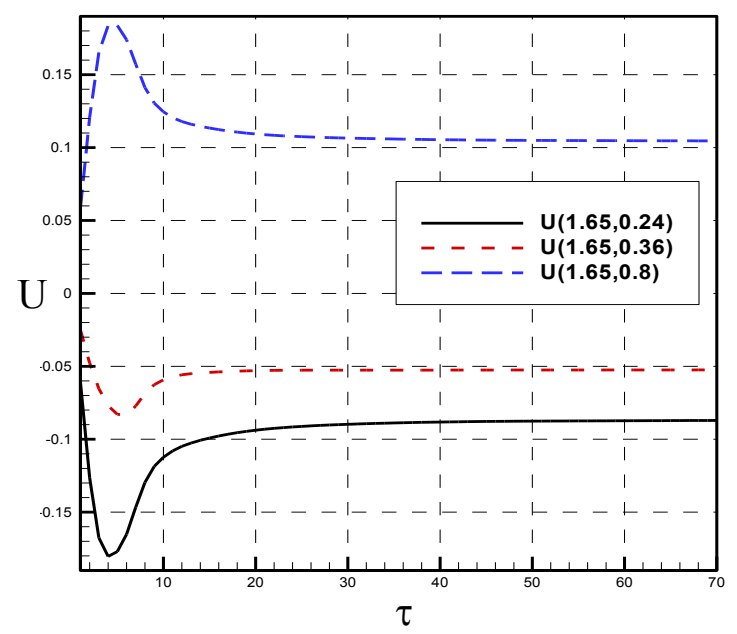

Fig 5: Plots of horizontal velocity versus dimensionaless time at three points $\mathrm{A}(0,0.8), \mathrm{B}(1.65,0.8), \mathrm{C}(1.65,0.9)$ for $\mathrm{Ra}=10^{5}, \mathrm{X}=0.5, \mathrm{~K}=2$

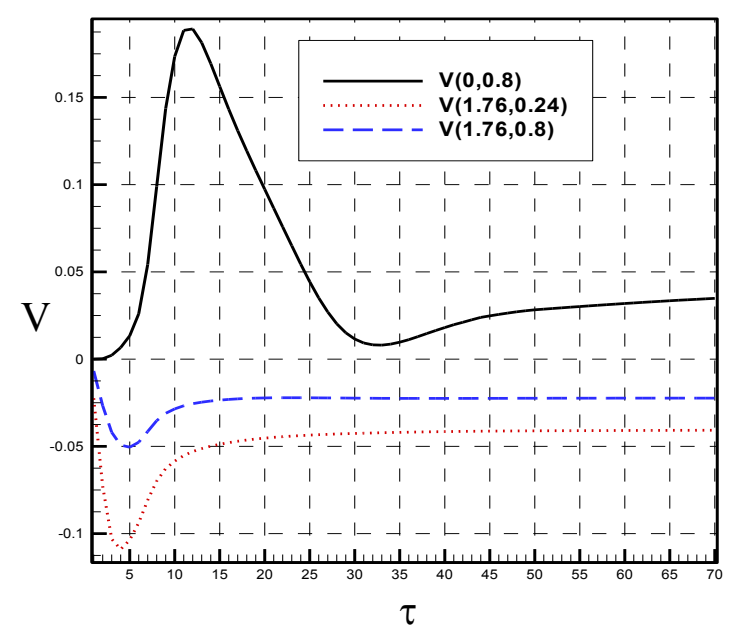

Fig 6: Plots of vertical velocity versus dimensionaless time at three points $\mathrm{A}(0,0.8), \mathrm{B}(1.65,0.8), \mathrm{C}(1.65,0.9)$ for $\mathrm{Ra}=10^{5}, \mathrm{X}=0.5, \mathrm{~K}=2$

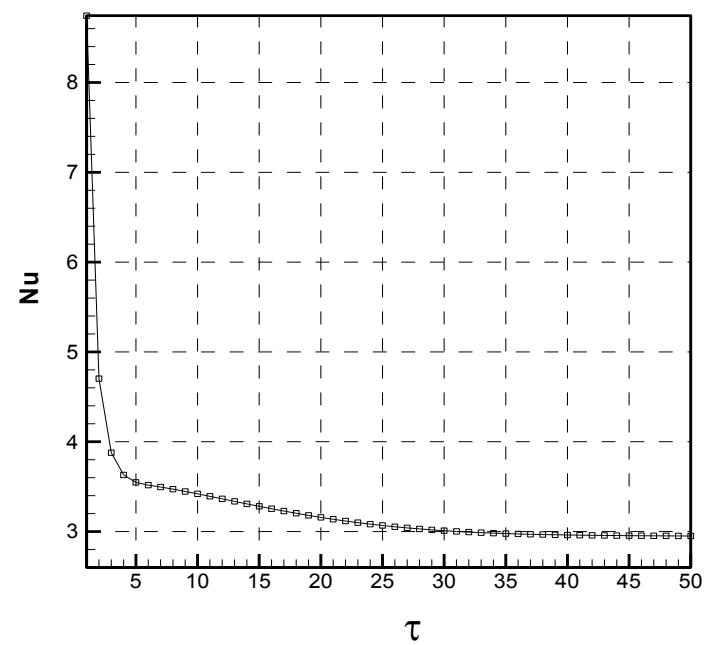

Fig 7: Transient average Nusselt number along the hot-vertical wall for $\mathrm{Ra}=10^{5}, \mathrm{X}=0.5, \mathrm{~K}=2, \operatorname{Pr}=7.0$

Fig.6 illustrated the plots of vertical velocity versus dimensionaless time at three several selected points for $\mathrm{Ra}=10^{5}, \mathrm{X}=0.5, \mathrm{~K}=2$. The plot show that the vertical velocity raises speedily in the first step time $\tau<10$ and stagnate after this time, except for the point $(0,0.8)$ (upper region above the inner cylinder), that take more time to reach the study state, because the thermal wave takes time to reach this region

\subsection{Heat transfer}

The transient variations of the average Nusselt numbers at the hot wall at several time instants are shown in Fig. 7 for $\mathrm{Ra}=10^{5}$ and $\mathrm{X}=0.5$. The results indicate that the thermal heat transfer is great during the first moments before $\tau<10$ compared with the average Nusselt values for $\tau>10$ because of the temperature gradient between the active walls and the fluid at $(\theta=0)$. As one goes forward in time $\tau>25$, 
the fluid temperature tends to equilibrium. The heat transfer has been decreased by the flow steady-state.

\section{Conclusion}

In this paper transient development of isotherms, temperature and velocity fields in vertical annular cylindrical enclosures driven by the thermal action buoyancy forces was numerically investigated. The nondimensionalized conservation equations have been solved using the finite volume method (FVM). On the basis of present simulations, the following conclusion can be made.

- The evolution of the flow pattern and the heat transfer were found to be significantly influenced by the buoyancy thermal forces.

- The temperature profile at several selected points increase in the first step time $\tau \leq 10$ and stagnate after this limit of step time (steady states).

- The horizontal and vertical velocity plots rise in the first step time and reduce when steady states have been reached.

- The thermal heat transfer is great during the first moments before $\tau<10$.

\section{Reference}

1 G. de Vahl Davis and R. W. Thomas. "Natural convection between concentric vertical cylinders, high speed computing in fluid dynamics", Phys. Fluids, suppl. II, pp 198-207, (1969).

2 V. Prasad and F. A. Kulacki, "Free convection heat transfer in a liquid-Filled vertical annulus", J. Heat Transfer, vol. 107, pp 596-602, (1985).

3 R. Kumar and M. A. Kalam., "Laminar thermal convection between vertical coaxial isothermal cylinders", Int. J. Heat Mass Transfer, vol. 34, pp 513524, (1991).

4 V. Prasad, "Numerical study of natural convection in a vertical porous annulus with constant heat flux on the inner wall", Int. J. Heat Mass Transfer, vol. 29, no. 6, pp 841-853,(1986).

5 Y.L. He, W.Q. Tao, Z.G. Qu, Z.Q. Chen, "Steady natural convection in a vertical cylindrical envelope with adiabatic lateral wall", Int. J. Heat and Mass Transfer, Vol. 47, pp 3131-3144, (2004).

6 Asif Hussain Malik and S. Khushnood, "Experimental and numerical study of buoyancy driven flow within a bottom heated vertical concentric cylindrical enclosure", Natural Science, Vol.5, No.7, pp 771-782, (2013).

7 Nilesh B.Totala and Mayur V.Shimpi, "Natural convection characteristics in vertical cylinder", Int. J. Engineering And Science, Vol.3, Issue 8, pp 27-31, (2013).

8 R. Hosseini. A. Rezania. M. Alipour. L. A. Rosendahl, "Natural convection heat transfer from a long heated vertical cylinder to an adjacent air gap of concentric and eccentric conditions", Heat Mass Transfer, vol. 48, pp 55-60, (2012).
9 K. Choukairy, R. Bennacer, H. Beji, and S. Jaballah, "Transient behavior inside a vertical cylindrical enclosure heated from the side walls", Numerical Heat Transfer, Vol. 50, Part. A, pp 773-785, (2006).

10 P. Venkata Reddy, G.S.V.L.Narasimham, "Natural convection in a vertical annulus driven by a central heat generating rod", Int. J. Heat and Mass Transfer, vol. 51, pp 5024-5032, (2008).

11 M. Sankar. Soojin Hong. Younghae Do. Bongsoo Jang, "Numerical simulation of natural convection in a vertical annulus with a localized heat source", Meccanica, vol 47, pp 1869-1885, (2012).

12 Sheng Chen et Jonas Tölke, "Numerical investigation of double-diffusive (natural) convection in vertical annuluses with opposing temperature and concentration gradients", International Journal of Heat and Fluid Flow, vol 31, pp 217-226, (2010).

13 Jiten C Kalita et Anoop K Dass, "Higher order compact simulation of double-diffusive natural convection in a vertical porous annulus", Engineering Applications of Computational Fluid Mechanics, vol 5, no 3, pp 357371, (2011).

14 M. Sankar et al, "Numerically investigated the Thermosolutal convection from a discrete heat and solute source in a vertical porous annulus", Transp Porous Med, vol 91, pp 753-775, (2012).

15 Rajesh Sharma et al, "Numerical Simulation of Transient Free Convection Flow and Heat Transfer in a Porous Medium", Mathematical Problems in Engineering, Volume (2013).

16 M. Sankar et al. Natural Convection in a NonUniformly Heated Vertical Annular Cavity, Defect and Diffusion Forum, Vol. 377, pp. 189-199, (2017).

17 K. Choukairy, R. Bennacer, H. Beji, and S. Jaballah. Transient behavior inside a vertical cylindrical enclosure heated from the side walls, Numerical Heat Transfer, Vol. 50 Part. A, pp 773-785, (2006).

18 A. K. Sharma, K. Velusamy, C. Balaji, "Conjugate transient natural convection in a cylindrical enclosure with internal volumetric heat generation", Annals of Nuclear Energy, vol. 35, pp 1502-1514, (2008).

19 Amitesh Kumar. Mitesh Vegad. Subhransu Roy, "Onset of unsteady axi-symmetric laminar natural convection in a vertical cylindrical enclosure heated at the wall”, Heat Mass Transfer, vol 46, pp 421-429, (2010).

20 D. E. Ameziani et al., "Analysis of the TimeDependent Heating on the Natural Convection from a Vertical Open Ended Porous Cylinder", Defect and Diffusion Forum, Vols. 273-276, pp 28-33, (2008).

21 S.Patankar, "Numerical Heat Transfer and Fluid Flow", Hemisphere, New York, (1980). 